\title{
IDEAS SOBRE LA NARRATIVA DE VISSARIÓN BELINSKI
}

\author{
José R. Valles Calatrava
}

Universidad de Almería

\section{LA FIGURA DE BELINSKI}

Vissarión Grigórievich Belinski (Sveaborg, 1811-Petersburgo, 1848) es, sin duda, un crítico tan afamado y conocido en Rusia y en el mundo eslavo - e incluso en algunos países de la antigua esfera occidental como Inglaterra o Italia - como casi desconocido en el ámbito hispánico: los textos del padre de la crítica rusa y fundador de la que podría denominarse crítica social-realista, continuada por sus epígonos Chernishevski, Dobroliúbov y Písarev, aún no han podido leerse en español ${ }^{1}$.

1 Aparte de las numerosas ediciones de sus obras completas y escogidas en ruso, puede accederse a una selección de sus textos metaliterarios en Belinski, Textes philosophiques choisis (Moscú, 1948) (Selected Philosophical Works, con introducción de M. Yovchuk), Über die Klassiker der Russischen Literatur (1953) y Essais critiques, con introducción de V. Kouleshov y traducción de A. García (1976). También puede 
Curiosamente, en la actualidad, como consecuencia de esos movimientos pendulares sociohistóricos, políticos e ideoculturales, tan comunes en Rusia como en la propia España, la figura de Belinski - y la de sus seguidores-, tan influyente y entronizada en Rusia durante tanto tiempo a partir de las alusiones de Lenin - por vez primera en 1914 , en el artículo «Sobre el pasado de la prensa obrera en Rusia» publicado en Rabóchiy - a los que llamó revolucionarios demócratas y de la divulgación de su pensamiento por la historiografía socialista oficial, ha caído en la consideración evaluativa inversa: los negativos y a veces duros juicios sobre Belinski de los críticos conservadores de Veji o de Aichenwald y Rozánov a principios de siglo, culpándole casi de la primera intentona revolucionaria, son hoy asumidos por gran parte del pensamiento ruso antisocialista; por ejemplo, por escritores tan conocidos como Astáfiev.

En cualquier caso, al «impetuoso Vissarión», como era denominado, cabe el mérito de haber sido el primer gran teórico y crítico ruso - en realidad, el fundador de la crítica rusa- de haber descubierto o encumbrado con sus artículos a numerosos literatos rusos hoy reconocidos como de primera fila como Pushkin, Gógol o Turguénev, de haber fundamentado la teoría estética del realismo que -con variaciones - tanto juego iba a dar en Rusia y toda Europa no sólo en la tendencia de la crítica social-realista rusa decimonónica sino en la misma teoría marxista del arte, de haber vinculado la dimensión ficcional y autónoma - aunque vinculada a la reproducción creativa y no mimética de la realidad - de la literatura con su papel ético y social, de haber dispuesto de una autoridad y de haber ejercido un magisterio e influencia en el pensamiento ruso del XIX difícilmente parangonables. En sucesivas revistas como El telescopio (Telescop), El observador moscovita (Moskovski Nabliudatel), Apuntes nacionales (Otéchestvennie Zapiski) y El Contemporáneo (Sovreménnik), Belinski, ocupándose $^{2}$ de autores extranjeros como Hoffmann, Sue, Shakes-

verse Lo Gatto (ed.) (1925). En español, podrán leerse próximamente algunos de sus trabajos críticos más representativos en Valles y Davidenko (2000).

2 Sus principales trabajos sobre teoría y crítica literaria, aparecidos en las citadas revistas, son los siguientes: Sueños literarios (1834), El relato ruso y los relatos de Gógol (1835), Poesía de V. Benedíktov (1835), Poesía de A. Koltsov (1835), De la crítica y las opiniones literarias de "El observador moscovita» (1836), "Hamlet». Drama de Shakespeare. Mochálov en el papel de Hamlet (1838), "Aniversario de Borodinó", de Zhukovski (1839), Menzel, crítico de Goethe (1840), "¿Qué desgracia el ingenio!», de Griboiédov (1840), "Un héroe de nuestro tiempo», obra de $M$. Lérmontov (1840), Poesía de M. Lérmontov (1841), Literatura rusa en 1840 (1841), Curso teórico-crítico de literatura rusa (1841), División de la poesía en géneros y variedades (1841), 
peare, Goethe o Scott, y rusos como Pushkin, Lérmontov, Gógol, Turguénev, Zhukovski, Griboiédov, el primer Dostoievski y muchos otros, centrándose asimismo en fijar los periodos y figuras canónicas de la historia literaria y en otras cuestiones de poética y teoría literaria, desarrolló un pensamiento que, si no original por sus filiaciones filosóficas y su semejanza con el de otros autores europeos del realismo, sí ofrece un corpus de aportaciones bastante sólidas y sistemáticas que, como veremos, aparte de sus influencias y continuaciones, merece ser muy tenido en cuenta por sí mismo.

\section{CARACTERES Y BASES FILOSÓFICAS DE LA CRÍTICA SOCIAL-REALISTA Y DEL PENSAMIENTO DE BELINSKI}

De los tres grandes ejes de coordenadas que atraviesan el pensamiento ruso original del siglo XIX —el elitismo/popularismo, la ortodoxia/heterodoxia y el eslavofilismo/occidentalismo - la que podría llamarse crítica social-realista - las enseñas del realismo y del papel social del arte son sus dos banderas comunes- opta fundamentalmente por los últimos ejes.

Olga Nóvikova (1997: 36) plantea cómo la historiosofía rusa debía resolver el sentido de la reforma de Pedro I optando por la vía ilustrada y moderna europea o por la singularidad eslava rusa: la crítica social-realista, con Belinski al frente, adopta la posición europeísta y popularista. Precisamente, Belinski diferenció entre lo nacional y lo popular en relación a la oposición hegeliana entre lo formal y lo sustancial; y en un temprano trabajo I. Lotman (1997: 532-33) encuentra en el materialismo filosófico del XIX, combinado con las particularidades del pensamiento decimonónico ruso, las claves de la ideología revolucionario demócrata:

Las lecciones del desarrollo burgués en Europa, el espectáculo de la lucha abierta de clases, la salida a la palestra teórica de ideas de la dialéctica y del socialismo, todos esos acontecimientos coincidieron con el periodo

Aventuras de Chichikov o "Almas muertas» (1842), Obras de Alexandr Pushkin (184346), Una ojeada a la literatura rusa del año 1846 (1847), Carta a Gógol (1847), Una ojeada a la literatura rusa del año 1847 (1848). 
cuando el proceso histórico propiamente ruso planteaba tareas de lucha contra la servidumbre y originaba inminentemente la ideología revolucionaria democrática con sus características inherentes: el carácter normativo, el antropologismo, la idea del mal social como producto de la «sinrazón» y, junto con ello, su apasionado rechazo de la opresión (...) La combinación compleja de historicismo con antropologismo metafísico era precisamente lo que constituía uno de los principales rasgos originales del realismo ruso del siglo XIX. A pesar del carácter históricamente limitado de ese método, la presencia del antropologismo y la normatividad estaba estrechamente vinculada también a los aspectos fuertes de la literatura rusa del XIX. Condicionó ese énfasis de renuncia, de la severa aspiración a la verdad, a la pureza moral, ese «desenmascaramiento de todo y de todos».

El nacimiento de esta tendencia crítica se remonta a los años 40 , cuando, en unas condiciones peculiares de falta casi absoluta de libertad de palabra, surgió a partir de Belinski una actividad crítico-literaria que excedía la dimensión estrictamente artística para ofrecerse como un discurso omnicultural, interesado no sólo por lo literario sino asimismo por lo social, lo filosófico, lo estético y lo político; el término ruso de publitsistika, «crítica de la conciencia pública», revela bastante adecuadamente su función de aldabonazo a las conciencias y su objeto omnicultural. Lejos así de las posiciones esteticistas del arte por el arte, consciente de la inexistencia de cualquier neutralidad discursiva y del papel sociohistórico de la literatura, la crítica social-realista, paulatina pero progresivamente, conllevando parejos su compromiso y fin sociopolítico con la apuesta por una estética realista cada vez más mimética, se hará eco de la dimensión de crisol sociocultural de la literatura y de la constitución de la misma como espacio en el que apoyar las actitudes sociopolíticas y los aldabonazos a la conciencia de la crítica. No cabe duda de que en Rusia, en esos momentos y no sólo los cuatro principales críticos social-realistas, se contemplaba la literatura como un crisol, como un laboratorio donde se iba experimentando y fraguando la individualidad nacional del pueblo y el destino patrio y de toda la humanidad. La crítica rusa en general era novedosa y original, porque era consciente de su misión ética y social, de su responsabilidad ante la nación y el pueblo. Como señala Bowman (1954: 6), «llegó a ser función de la inteligencia rusa mantener constante supervisión de los asuntos nacionales generalmente mediante la emisión de juicios críticos - artísticos, filosóficos, políticos- sobre el estado completo de la vida social y cultural rusa». Acaso por tal motivo, mientras en otros países europeos occidentales diferentes talentos se dedicaban a distintos campos del conocimiento, en Rusia tantos y tantos críticos y escritores ocuparon el espacio de la crítica literaria periodística. 
Pero, pese a la misma raíz de la crítica social-realista, no son nunca idénticas las claves teóricas desde las que se generan los distintos textos y opera el pensamiento de cada uno de los cuatro críticos fundamentales: compartiendo una misma línea común en la influencia del proyecto ilustrado de la modernidad, el peso del materialismo dieciochesco, la visión de la interrelación entre la serie sociocultural y la literaria o la defensa estética del arte realista (incluso el reconocimiento expreso del magisterio de Belinski), se aprecian, no obstante, notorias diferencias entre la base romántica del idealismo objetivista que prima en casi toda la producción de Belinski o la mayor influencia del materialismo antropológico de Feuerbach en Chernishevski y Dobroliúbov e incluso del determinismo positivista en Písarev, entre el realismo más formal de Belinski y el más genético o mimético (Villanueva, 1992) de Chernishevski y Písarev, entre las posiciones políticas más vinculadas al socialismo utópico de Chernishevski, Dobroliúbov y el Belinski de los últimos tiempos y el nihilismo de Písarev.

En el pensamiento de Belinski y en el de toda la crítica social-realista, además de las propias singularidades ideoculturales rusas del XIX, tiene un peso esencial la filosofía alemana. Como indica Lo Gatto (1956: 195), si durante el siglo XVIII la escasa crítica rusa había tenido como referencia el clasicismo francés y, en concreto, la Poética de Boileau, el siglo XIX se caracteriza por el peso del pensamiento alemán, tanto en Galich — condiscípulo de Schelling - en los primeros años como, con posterioridad, en el mismo Belinski. Ya Plejanov (Yovchuk, 1956: XV) destacó en el pensamiento del crítico ruso una serie de cinco etapas de influencia de la filosofía alemana sucesivamente marcadas por Schelling, Fichte, Hegel, la izquierda hegeliana y Feuerbach.

Y, efectivamente, las raíces de la teoría literaria de Belinski se encuentran en el romanticismo, fundamentalmente alemán y hegeliano, en una línea próxima al idealismo objetivista que inspiró asimismo los planteamientos de Taine. El crítico ruso evolucionó desde la filosofía clásica alemana, desarrollando, a partir de Schelling, Fichte y sobre todo Hegel, como indica el mismo Lo Gatto (1925: 14), una estética bastante original que iba por delante de la alemana del momento. Durante algún tiempo se situó también particularmente bajo la influencia de Roetscher (a esa época pertenece su ensayo sobre $U n$ héroe de nuestros tiempos, de Lérmontov), pero pronto renunció a esta línea abstracta e impersonal en la filosofía hegeliana; además, frente al respeto que le merecían las ideas directas de Hegel, en sus cartas demuestra su escaso aprecio hacia los seguidores del gran filósofo. 
Más de una vez Belinski, que no hablaba ningún idioma extranjero, fue acusado de no conocer la filosofía de Hegel en lengua original, de comprenderla a través de la mediación de amigos. Sin embargo, Hegel fue asimilado por Belinski profundamente. Con la influencia hegeliana se relaciona el giro que dieron los fundamentos estéticos expuestos en los ensayos de Belinski desde el idealismo abstracto a la realidad, que atrae toda la atención del crítico concibiéndola primeramente como la realización de la idea sobrenatural. Hasta tal punto, en una cierta etapa, se identificó Belinski con Hegel que, confundiendo la realidad con lo existente a partir de la fórmula «todo lo real es razonable», tendió a una aceptación de la historia que le llevó a no cuestionar el zarismo y la estructura social rusa, como había hecho Hegel con la monarquía prusiana. Escribe Kuleshov (1976: 13) al respecto:

\begin{abstract}
La asimilación de Hegel conducía primero a Belinski a una denominada «reconciliación filosófica» con la realidad rusa. Se seguía que Belinski, adversario del régimen establecido, se había «reconciliado» con el orden existente demostrando los buenos fundamentos de la autocracia en Rusia. Este estado mental encontró su expresión en los artículos Aniversario de Borodino (1839), Menzel, crítico de Goethe (1840).
\end{abstract}

Pero el carácter terrible y deforme de la realidad circundante no dejaba a Belinski detenerse en la aceptación y la reconciliación con la realidad. Comenzó a salir al primer plano la preocupación por el problema de la individualidad y se gestó una evolución hacia un personalismo cada vez más pronunciado. A partir de ahí Belinski reelabora y reformula sus ideas, aun con la misma base hegeliana, para trascender la justificación de la realidad — de la situación sociopolítica— de su momento como encarnación del espíritu. Belinski va abandonando el idealismo y fatalismo hegeliano y profundiza en el planteamiento dialéctico: la comprensión de que hay factores caducos y negativos en la realidad frente a los positivos y progresistas, el entendimiento de que hay distintas tendencias y planteamientos en el seno de la misma literatura; de este enfrentamiento surge un planteamiento de futuro guiado por la racionalidad, el cambio, el desarrollo, el perfeccionamiento, tanto en la sociedad (hacia el socialismo, cada vez más radical) como en la literatura (hacia el realismo, como mejor método de conocimiento y representación de la realidad objetiva).

Como plantea Yovchuk (1956: XXX-XXXI), en su última etapa se da su transición del idealismo al materialismo: entre 1841-1844 va distanciándose y criticando la filosofía de la historia hegeliana cada vez 
más, y hacia 1844 Belinski entra en contacto indirecto con las ideas del materialismo antropológico de Feuerbach y se vuelve cada vez más radical y materialista, encontrando en la determinación de lo espiritual por lo físico y de la conciencia por la realidad las claves de su pensamiento estético y social.

\section{LA «ESTÉTICA EN MOVIMIENTO» DE BELINSKI}

De esta forma denominaba Belinski su propia teoría y crítica literaria, algunos de cuyos conceptos fundamentales deben exponerse aquí para mejor entender su visión de la narrativa.

El primero de los grandes ensayos de Belinski ya da una definición de lo que es para él la literatura muy entroncada con dos de las ideas generalizadas en todo el movimiento romántico, las nociones de volkgeist o espíritu nacional-popular y la del creador/genio:

[...] llámase literatura el conjunto de tal género de obras artístico-verbales, que son fruto de la libre inspiración y esfuerzos conjuntos (aunque no concertados) de personas creadas para el arte, que respiran para el arte sólo y que dejan de existir fuera de él; que expresan y reproducen plenamente en sus bellas obras el espíritu del pueblo entre el cual son nacidos y educados, cuya vida viven y cuyo aliento respiran; que expresan en sus creaciones su vida interior hasta las profundidades y los latidos más ocultos.

En este trabajo de 1834, Sueños literarios, Belinski opone la verdadera literatura, la generada mediante una acción de la genuina alma creadora y el talento autorial, a la baja literatura, la que «se escribe a brocha gorda [y] su finalidad es una venta provechosa». A lo largo de sus principales trabajos - desde Sueños literarios, pasando por El relato ruso y los relatos de Gógol hasta los famosos resúmenes anuales de los años cuarenta-, Belinski insiste en esa oposición entre la literatura grande y verdadera y la literatura que sólo aparenta serlo, entre la obra literaria auténtica y la falsa.

La condición primera y el indicio de una obra literaria auténtica es la presencia del contenido, de una idea que es a la vez el motor de la trama y las acciones de los personajes a través de las cuales se realiza. En un planteamiento claramente hegeliano («el arte es expresión sensible de la idea»), Belinski considera que el pensamiento debe estar 
inseparablemente ligado a la forma, es decir, que el modo de exposición y de organización del material deben ser tales que permitan expresar la idea con la mayor plenitud y precisión: «La poesía es pensamiento en imágenes, y por eso en cuanto que la idea, expresada en la imagen, es inconcreta, falsa, incompleta, la imagen necesariamente no será artística». La visión de la obra literaria de Belinski como un todo orgánico y del arte como conocimiento concreto, sensible, remite, como indica Wellek (1972: 352), a la herencia de las teorías estéticas clásicas alemanas.

La segunda cualidad o condición de la verdadera literatura es lo que Belinski llamó «realidad», es decir, la presencia de un referente de la vida real transformado de forma peculiar por el arte, que nos hace creer en lo que nos comunica una obra como en algo que tiene su propia existencia real. A diferencia de Chernishevski, Belinski nunca se plantea qué es más bello, si lo que percibimos directamente en la realidad o lo que nos llega por mediación del arte. En una posición de un realismo formal o imaginativo antes que genético o mimético, Belinski es consciente de que la «realidad» del arte es otra, distinta, no idéntica a la «realidad real», si bien entiende que tal «realidad artística» recibe su legitimidad en la medida en que consigue captar lo esencial de la realidad circundante y externa. Replanteando la idea hegeliana de todo lo no real y sustancial que hay en la realidad accesible a nuestros sentidos, escribe: «El poeta no debe expresar lo particular, lo accidental, sino lo general y lo necesario». Salvo en la etapa de mayor materialismo e influencia de Feuerbach, ya bastante tardía, el concepto de realismo de Belinski deriva de Hegel y se fundamenta en el idealismo objetivista: la consideración de que el arte es pensamiento en imágenes, la idea realizada en forma sensitiva o accesible a los sentidos, la dialéctica del contenido y la forma, la misma idea de los tres estadios artísticos — simbólico, clásico y romántico- que reelabora Belinski para establecer las tres grandes épocas del arte ruso - clasicismo, romanticismo, realismo- tienen un claro anclaje hegeliano.

El fundador de la crítica realista rusa y legitimador de la gran novela realista rusa no utilizó nunca directamente el término realismo, que empleó en Rusia por primera vez Annénkov en la primera memoria anual del panorama editorial, publicada en El Contemporáneo inmediatamente después de la muerte del crítico, en 1849. El propio Belinski utilizó - eso sí con el mismo sentido estético y aparte de la palabra «realidad»— los sintagmas de «poesía real», «escuela real» y también «escuela natural». Como hemos visto, el realismo para Belinski, enten- 
dido en una primera etapa desde el idealismo objetivista como oposición estética a la herencia de la literatura y la crítica clasicistas en Rusia, concebido en una segunda época y desde el materialismo como una determinación de la realidad sobre la conciencia, nunca se planteó tan mimética y fotográficamente como en Chernishevski o Písarev; la referencia obligada del arte a la realidad no implicaba ni una subsidiariedad o supeditación de este respecto a aquella (igualdad de las series realidad/literatura) ni un calco mimético absoluto (autonomía de las series realidad/literatura), sino una necesidad estética — «donde está la vida, allí está la poesía», dirá- de transcribir la realidad en la obra ficcional con la mediación de la actividad autorial. Ya en El relato ruso y los relatos de Gógol Belinski plantea, con respecto al realismo, la doble cuestión de que el arte debe reflejar la vida «como una lente convexa» $\mathrm{y}$ «desde un punto de vista» $\mathrm{y}$ de que este reflejo es una construcción artística para la que conviene elegir los elementos esenciales de la vida (Valles y Davidenko, 2000):

\begin{abstract}
Así pues, este es el otro lado de la poesía, la poesía «real», la poesía de la vida, la poesía de la realidad y, finalmente, la poesía verdadera y genuina de nuestra época. Su característica distintiva consiste en ser fiel a la realidad; no vuelve a crear de nuevo la vida, sino que la reproduce, la reconstruye y, como una lente convexa, refleja, bajo un punto de vista, sus distintos fenómenos, escogiendo aquellos que son precisos para componer un cuadro completo, vivo y único.
\end{abstract}

La tercera característica de la verdadera literatura es su función social y su dimensión moral. Reconociendo la dialéctica de la libertad y la determinación y de lo consciente e inconsciente en el proceso creativo, Belinski defendió siempre los principios de la libertad creativa y el valor artístico contra cualquier clase de dogmatismo ideológico o diferencia de Chernishevski y Písarev- utilitarismo práctico. Ello, sin embargo, no estaría renegado con la función social de la literatura ni podría dar paso a un «arte por el arte» rechazado por él; la dimensión ética de la literatura (incluida la propia: su especial predilección por Gógol no impidió que se rebelase contra Pasajes escogidos de la correspondencia con amigos) no se concibe como algo externo, desligado de lo estético, impuesto desde fuera a la literatura, sino como un factor inherente a la misma:

Separar la cuestión de la moral de la cuestión del arte es tan imposible como descomponer el fuego en luz, calor e intensidad de combustión (...) Lo que es artístico, es moral; lo que no es artístico, puede no ser inmoral, 
pero no puede ser moral. Por consiguiente, la cuestión sobre la moralidad de una obra de arte debe ser secundaria y deducirse de la respuesta a la pregunta si es la obra verdaderamente artística.

Con este papel social del arte se vinculan asimismo sus ideas sobre la necesidad de promover la educación artística y científica, sobre la conveniencia de auspiciar el componente formativo en el pueblo para mejorar su cualificación y, a la postre, su autoconciencia y capacidad sociopolítica de operar sobre la misma realidad. En este plano Belinski recoge la tradición del horizonte moderno surgido de la Ilustración, pero también, como apunta Yovchuk (1956: XIII), del fundador de la ciencia y filosofía materialista rusa Lomonosov, al igual que el pensamiento de Radischev y los decembristas se encontraría en la raíz de su visión política de oposición a la autocracia y a la servidumbre.

La siguiente y última condición indispensable de una literatura auténtica es su carácter nacional o, mejor, popular. Aquí Belinski usa el concepto de popular-nacional desde el resabio romántico de volkgeist, vinculándolo tanto al talento autorial como a su interés y dimensión universal:

\begin{abstract}
En la actualidad el carácter popular se ha convertido en el primer valor de la literatura y en el mérito supremo del poeta. Llamar popular (nacional) a un poeta significa ahora engrandecerlo. $Y$ por eso todos los que escriben ahora en verso y en prosa quieren a cualquier precio hacerse «populares» y luego ya talentosos. Pero, con todo, aquí como por doquier, hay muchos más escritores ineptos que talentosos, y mucho menos de los últimos que de los que son al mismo tiempo talentosos y populares. La causa del fenómeno es que el carácter popular es también una especie de talento, que como todo talento viene dado por la naturaleza (...) Es obvio que es popular sólo aquella literatura que al mismo tiempo es literatura universalmente humana; y es verdaderamente humana sólo aquella literatura que al mismo tiempo es popular. Una cosa no puede ni debe existir sin la otra.
\end{abstract}

Muy pocos autores niegan que Belinski tuviese «gusto» $u$ «olfato» de crítico, incluso los más malintencionados u opuestos a Belinski en su última etapa, que transcurrió bajo el signo de su máxima radicalidad en lo socialista y lo realista: tal vez entre esos pocos haya que contar a V. Toporov. Prácticamente todos sus contemporáneos, incluyendo quienes no compartían sus planteamientos estéticos y aun los que no recibieron sus críticas favorables (Goncharov, el primer Dostoievki de El doble), reconocían su talento crítico, fuertes juicios estéticos —el «impetuoso Vissarion»-y aportaciones teóricas. 
Ciertamente, Belinski no poseía un método crítico riguroso - a diferencia, por ejemplo, del positivista de Lanson-, ni tampoco una doctrina científica bien construida y articulada — se nutrió dispersa y asistemáticamente de la teoría romántica, básicamente en el sentido del idealismo objetivista hegeliano y luego del materialismo feuerbachiano-; sus sentimientos e intuiciones estéticas, pasadas por el tamiz de la meditación y el análisis, no obstante, le proporcionaron bastantes juicios certeros y lo salvaron de algunas interpretaciones excesivamente utilitaristas, como las que efectuaron sus propios epígonos (basta con comparar las valoraciones que hacen Belinski, Dobroliúbov y Písarev, por ejemplo, de la novela de Písemski Mil almas). En cualquier caso, es irrefutable que Belinski descubrió numerosos valores ahora indiscutibles de la literatura rusa: muchas de caracterizaciones de escritores rusos hechas por él suenan como si estuvieran escritas hoy mismo; Pushkin y Gógol no serían lo que son ahora para la cultura rusa si no fuese por Obras de Alexandr Pushkin y sus trabajos sobre el segundo; la relación de los valores literarios rusos creada por Belinski es la comúnmente aceptada hasta ahora.

\section{LAS IDEAS SOBRE LA NARRATIVA DE BELINSKI}

Una vez expuestas las bases filosóficas de las teorías belinskianas y su pensamiento y posiciones sobre la literatura, cabe pasar a revisar sus principales ideas y aportaciones sobre la narrativa, posiblemente el género más estudiado por él y el que considera el más moderno y propio del realismo.

En la serie de artículos titulados Sueños literarios -Elegía en prosa- (1834), aparecidos en el suplemento de El telescopio denominado El rumor (Molvá), Belinski repasa, a partir de una visión romántica, la literatura rusa previa partiendo de que no ha existido tal, ya que la nación y la sociedad, el pueblo, han seguido caminos divergentes y apenas se encuentran obras que efectivamente reproduzcan el verdadero y trascendente espíritu nacional ruso. Según Bowman (1954: 6769), en este trabajo se aprecia no sólo un planteamiento de su visión de la literatura en el eje de materialización y concreción que va desde la «idea eterna» a la «humanidad» y de ahí a la «nación» hasta el verdadero «poeta», sino asimismo un diagnóstico de la situación literaria rusa, marcada por la carencia precisamente del elemento intermedio «nación». Escribe Belinski (1956: 83-84): 
La historia de nuestra literatura es ni más ni menos que la historia de un esfuerzo abortado, mediante la servil imitación de patrones extranjeros, para crear una literatura propia; la literatura, no obstante, no es creada, se crea a sí misma como el lenguaje y las costumbres (...).

En esta serie, Belinski, preocupado por repasar las supuestas figuras y etapas de la literatura rusa (cinco periodos encabezados respectivamente por Lomonosov, Karamzin, Pushkin, el dominio de la prosa y Smirdin y con muy pocos autores realmente originales y trascendentes), expone pocas ideas sobre la narrativa: vincula al espíritu de las sociedades antiguas las epopeyas y relatos populares, analiza los valores de algunos fabulistas y novelistas (Krilov, Lazhechnikov, Bulgarin, Pushkin, Gógol, Smirdin, etc.), considera a la novela, en consonancia con las ideas hegelianas de la evolución de las formas en relación con el movimiento del espíritu, como la épica de los nuevos tiempos y atribuye al talento creador y la capacidad de captar el espíritu nacional la posibilidad de crear una novela de valía.

En 1835 apareció en El telescopio el artículo Del relato ruso y los relatos de Gógol, de mucho mayor calado en su reflexión sobre la narrativa porque en él funde las ideas schlegelianas y hegelianas para caracterizar la narrativa rusa contemporánea. A partir de la distinción de F. Schlegel sobre poesía ideal y real, Belinski considera que, frente a la epopeya antigua y la novela moderna, ideales y disociadas de la realidad, la nueva narrativa está marcada por el signo de la fidelidad a la realidad, de la reproducción y reconstrucción de la vida en un cuadro vivo y único como una lente convexa y bajo un cierto punto de vista. A partir de los planteamientos hegelianos, entendiendo que como cambia el espíritu así cambian las formas, Belinski traza una línea en la evolución formal que va desde el poema épico ideal al nuevo relato y la novela realista pasando por la novela fantástica moderna y el giro realista que le otorga Cervantes y hace resurgir Scott.

La novela y el relato son, pues, las nuevas formas de representación realista del mundo y ocupan un lugar de privilegio tanto porque lo han «conquistado» con respecto a los otros géneros como porque, con relación a la oda, al poema épico, a la fábula, al poema narrativo romántico y pushkiniano, lo «han matado todo» y «han absorbido todo». En estas ideas en germen sobre la capacidad de intertextualización de la novela, sobre su modernidad y actualidad, sobre su posición preeminente ganada tras lucha y canibalización de los otros géneros-que tanto recuerdan algunos aspectos de la teoría mucho más sistemática y 
desarrollada de Bajtín, particularmente la expuesta en Épica y novela (1989: 449-485) - , Belinski insistirá en otros trabajos, particularmente en su último estudio dedicado a revisar la literatura rusa de 1847 .

Nuestro crítico añade también la idoneidad y capacidad formal y de contenido de la novela de representar la realidad y sociedad contemporánea; escribe Belinski (Valles y Davidenko, 2000):

\begin{abstract}
A lo mejor la novela, es más cómoda para la representación poética de la vida. $Y$, en efecto, su volumen, sus límites son imprecisos hasta el infinito; es menos orgullosa, menos caprichosa que el drama, pues no nos seduce tanto con trozos o fragmentos como por su conjunto, y admite pormenores tales que, a pesar de toda su nulidad, si se observan por separado, tienen un sentido profundo y un caudal de poesía en relación con la obra entera, con su conjunto (...). Así pues, la forma y las condiciones de la novela son más cómodas para la representación poética del hombre analizado en su relación con la vida social, y es ahí donde reside, a mi parecer, el misterio de su extraordinario éxito, de su dominio absoluto.
\end{abstract}

En cuanto al éxito de la narrativa corta, del relato breve, Belinski, tras mencionar a sus escasos -en 1835- representantes rusos (Marlinski, Odóyevski, Pogodin, Polevoy, Pávlov y Gógol), destaca su coaptación de la brevedad y la rapidez con la intensidad y la condensación y vincula su surgimiento y su éxito a las nuevas condiciones sociales y al ritmo de vida -iya de antes de mediados del $\mathrm{XIX!-} \mathrm{He} \mathrm{aquí} \mathrm{un} \mathrm{fragmento} \mathrm{significativo} \mathrm{que} \mathrm{figura} \mathrm{a} \mathrm{continua-}$ ción del anterior:

Alguien ha dicho en alguna parte una frase excelente: «el relato es un episodio del poema infinito de destinos humanos». Es muy acertado; sí, el relato es una novela deshecha en mil pedazos, un capítulo arrancado de una novela. Somos gente ocupada, no paramos de agitarnos, de atarearnos, apreciamos cada minuto, no tenemos tiempo para leer libros grandes y largos: en suma, necesitamos un relato. La vida nuestra, la moderna, es demasiado variada, compleja, compuesta de mil partes: queremos que se refleje en la poesía como en un vaso biselado y anguloso, repetida millones de veces en toda clase de imágenes, y exigimos el relato. Hay sucesos, hay casos que, por así decirlo, no bastarían para un drama, no serían suficientes para una novela, pero que son profundos, que en un instante concentran tanta vida que no se podría exponer en siglos: el relato los capta y los recluye en su estrecho marco. En su forma tiene cabida cualquier cosa que usted quiera: un ligero ensayo de costumbres, y una burla mordaz y sarcástica del hombre y de la sociedad, y el profundo misterio del alma, y el juego cruel de las pasiones. Breve y rápido, ligero y profundo al mismo tiempo, va volando de un objeto al otro, desgrana la vida en partículas menudas y arranca hojas del gran libro de esta vida. Recojan estas hojas bajo la misma tapa de encuadernación: ¡qué libro tan extenso, qué novela tan enorme, qué poema tan complejo se compondría! 
También aquí empieza a plantear Belinski por primera vez su teoría de lo típico, de forma paralela a las ideas sobre los tipos y personajes de Balzac y con bastante similitud con las referencias al mismo concepto de Engels, de Dobroliúbov y luego de Lukács. En la noción belinskiana, la unidad de la idea y la forma en el ámbito de la estética se convierte en la teoría del tipo, como doble manifestación de lo general en lo individual y de lo real en lo literario; la tipización responde así tanto a la representación de la realidad por el arte como a la representación de lo común y general por lo particular e individual. Cuanto más alto es el nivel de tipización, más calidad tiene la obra literaria para el crítico ruso. El tipo sería, no un invento, sino un hecho extraído de la realidad como una generalización bien tamizada autorialmente y bien construida artísticamente, un hecho «pasado por la imaginación del poeta, iluminado con la luz de lo general». Aunque su concepto no se limita sólo a los personajes (precisamente habla de la veracidad y objetividad de las escenas de las novelas balzaquianas en contradicción con su suntuosidad para vestir), así lo plantea Belinski en relación con los mismos (Valles y Davidenko: 2000):

\begin{abstract}
Una de las características más distintivas de la originalidad creativa $o$, mejor decir, de la creatividad misma, consiste en el tipismo, si puede valer esta expresión, que es el sello, el timbre del autor. Creado por un verdadero talento, cada personaje es un tipo, y cada tipo para el lector es un desconocido conocido. No me diga: éste es un hombre de gran alma, de pasiones ardientes, de inteligencia amplia pero de razón limitada, que ama a su mujer con tanto frenesí que está dispuesto a estrangularla con sus manos si existe una ínfima sospecha de infidelidad; dígalo más sencilla y brevemente: ¡es un Otelo!
\end{abstract}

Durante varios años Belinski, además de reseñar obras sociales y de historia, centra su actividad en la crítica poética y dramática. Los trabajos «Poesía» de V. Benedíktov y «Poesía» de A. Koltsov (1835), De la crítica y opiniones literarias de "El observador moscovita» (1836), «Hamlet». Drama de Shakespeare. Mochálov en el papel de Hamlet (1838) o «Aniversario de Borodinó» de Zhukovski (1839) apenas contienen referencias notorias sobre la narrativa.

Menzel, crítico de Goethe (1840) insiste en la tesis de la vinculación del arte con la realidad y de la autonomía y sentido particular del arte por encima de su tendencia, sin que esto menoscabe su dimensión y utilidad tanto social como moral. Las ideas de totalidad artística y tipismo, de la reconstrucción de la realidad por la obra artística captando lo que de universal hay en la misma y pudiendo superar este a la naturaleza, 
de las imágenes artísticas en coherencia con el pensamiento (de clara filiación idealista alemana y básicamente schellinguiana), son las básicas para descalificar la sátira formulada como comedia "iQué desgracia el ingenio!» de Griboiédov (1840) - frente a la perfecta reconstrucción de la vida del Inspector general de Gógol-, y alabar la belleza salida de la conjunción de elementos y el efecto de totalidad proporcionados por las obras de Lérmontov en «Un héroe de nuestro tiempo» (1840) y Poesía (1841). En este último trabajo, modificando el orden hegeliano, defiende la aparición de la épica tras la lírica y antes de la dramática, y lo aplica no sólo al proceso histórico sino a la propia evolución escritural personal (hipotética) de Pushkin y Lérmontov.

Frente a lo que podría pensarse, los dos trabajos específicos sobre poética de Belinski, ambos de 1841 , no aportan nada nuevo esencial ni sobre la narrativa en particular ni sobre la literatura en general. La División de la poesía en géneros y variedades, recogiendo las ideas del idealismo alemán, plantea nuevamente la novela como forma reciente y adecuada al actual espíritu de la época de la antigua épica: Scott sería el nuevo Homero. La breve Idea del arte acepta y ejemplifica los tres estadios hegelianos de evolución de la humanidad y del arte, intentando demostrar su definición del arte como punto de partida (Belinski, 1956: 180):

\footnotetext{
El arte es la inmediata contemplación de la verdad, o un pensamiento en imágenes. Esta definición del arte, si se desarrolla, contiene la teoría completa del arte: su esencia, su división en clases así como las condiciones y esencia de cada clase.
}

Las aventuras de Chíchikov o «Almas muertas» (1842) santifica a Gógol como padre de la escuela natural y verdadero captador de la esencia de la realidad rusa. La crítica sobre Los misterios de París (1844) de Sue y el éxito de la traducción rusa de Stróyev analiza detenidamente la novela (sus personajes, trama, relación con la realidad sociopolítica francesa, su mala vinculación con los cuadros míseros de Dickens) para concluir que se trata de un éxito puramente económico y de engarce con el gusto de la multitud, de una mirada simplemente burguesa ( sic) - lastimera y nada comprometida - sobre la vida de los ambientes pobres y sórdidos parisinos y que muestra una enorme falta de talento en la reproducción de la realidad (sin capacidad de alcanzar el tipismo) y en la construcción de los personajes. Así cierra Belinski su crítica (Valles y Davidenko, 2000): 
Pero la idea lanzada por el genio se asimilaría demasiado despacio si no fuese recogida al vuelo por dones y talentos cuya predestinación es mediar entre el genio y la multitud. Incluso deformando y vulgarizando la idea del genio, la acercan precisamente así al entendimiento de la multitud. Si Eugène Sue hubiese escrito la novela sin adornos melodramáticos, con sencillez y naturalidad, rigurosamente fiel a la realidad, lo habrían apreciado sólamente aquellos para quienes la idea que contiene no es ninguna novedad, y no lo habrían leído aquellos para quien su idea sí es una absoluta novedad. Por supuesto, Eugène Sue no hubiese podido escribir mejor aunque quisiera, pero si logró éxito fue porque su talento no le sienta ancho a decenas y centenares de miles de lectores, y por eso estas decenas y centenares de miles de lectores piensan ahora en lo que no han pensado antes, y saben lo que antes no sabían.

Su siguiente ensayo, Las obras de Alexandr Pushkin, es una extensa serie de once artículos aparecidos entre 1843 y 1846 en Apuntes nacionales, donde se pasa revista a la literatura rusa desde Derzhavin a Pushkin (tres primeros), se examina la crítica rusa y el concepto de pathos del poeta — «una pasión encendida en el alma humana por la idea y que aspira siempre a la idea»- (quinto capítulo) y se analiza la producción literaria pushkiniana (el resto). En los artículos octavo y noveno, dedicados a Eugenio Oneguin —el décimo se centra en Boris Godunov-, califica estas obras de poemas narrativos de carácter histórico al modelo de Byron, pues comparten una misma forma en la manera de narrar, la mezcla de prosa y poesía, las digresiones y autoinvocaciones del poeta y la fuerte presencia de la voz autorial, si bien sería distinto su contenido, ya que los poemas de Pushkin reproducen no sólo de forma realista (se considera desde entonces la primera novela realista rusa) la vida de esos momentos sino el propio espíritu, la propia esencia y manera rusa de ver el mundo. Escribe nuestro crítico (Valles y Davidenko, 2000):

Y la primera obra tal, nacional y artística, fue Eugenio Oneguin de Pushkin (...). Comprendió que la época de los poemas épicos había pasado hace mucho tiempo y para representar la sociedad contemporánea, donde la prosa de la vida había impregnado tan profundamente la propia poesía de la vida, hacía falta una novela y no un poema épico. Cogió esa vida tal como era, sin sacar de ella sólo sus instantes poéticos; la cogió con todo su frío, con toda su prosa y vulgaridad. Y tal valentía sería menos sorprendente si la novela se hubiera emprendido en prosa, pero escribir semejante novela en verso en la época cuando en la lengua rusa ni siquiera había una sola novela importante en prosa, tal valentía, justificada con el enorme éxito, fue testimonio indudable de la genialidad del poeta.

Menos importancia con respecto al tratamiento de la narrativa ofrecen Pensamientos y observaciones sobre la literatura rusa (1846), 
donde explica la pobreza de la literatura rusa en la misma pobre realidad del país, la Carta a Gógol (1847), respuesta a sus Pasajes escogidos de la correspondencia con amigos, donde deja ver claramente su desacuerdo con la situación sociopolítica rusa en su giro hacia el socialismo y la influencia ya patente en toda esta última etapa del materialismo de Feuerbach, y la primera de sus revisiones, Una mirada a la literatura rusa de 1846, aparecida al año siguiente en El Contemporáneo, donde aplica el término «escuela natural» a la nueva estética realista, defiende al máximo la estética de ese signo - rechaza El doble de Dostoievski por sus excesos fantásticos-, opta claramente por la dimensión social del arte sin menoscabo de su propia entidad y valor autónomo, defiende la necesidad del doble carácter universal y nacional de la buena literatura - «Lo que es la personalidad en relación a la idea del hombre es la nacionalidad en relación con la idea de humanidad. En otras palabras, las nacionalidades son las personalidades de la humanidad» (Belinski, 1956: 395)—y repasa la producción más sobresaliente de la literatura del año previo.

Una mirada a la literatura rusa de 1847, aparecido en 1848 en dos capítulos en la misma revista que el anterior, es el último y uno de los principales y más famosos ensayos de Belinski. La primera parte se centra en la explicación de su método crítico, acepta la función social de la literatura rechazando el arte por el arte, y defiende la escritura novelística realista de la «escuela natural» que tiene a Gógol como figura cimera. El segundo capítulo, aún más interesante, analiza la producción literaria rusa del año anterior, sobre todo la narrativa (Iskander, Dostoievski, Turguenev, Druzhinin, etc.), centrándose de modo fundamental en el análisis de ¿Quién es el culpable?, de Herzen, una novela intelectual y de domostración artística de la idea a la que vaticina un éxito futuro Belinski (aquí se encuadraría luego ¿Qué hacer?, de Chernishevski), y Una historia corriente, de Goncharov, donde contrapone la construcción de los personajes del protagonista Adúyev y su tío como prototipos respectivos del hombre romántico y el positivista burgués.

Pero en esta parte se encuentra también expuesta, sintéticamente y muy en consonancia con lo planteado en Del relato ruso..., su concepción de la novela. Es realmente sintomático y sorprendente que Belinski hubiese desarrollado la teoría de la novela como forma de la realización más plena del método realista antes de que la novela rusa, el género por excelencia del realismo clásico del siglo XIX, llegase a su pleno apogeo en la obra de Dostoievski y Tolstoy: iprácticamente predijo el auge de la novela al menos veinte años antes de que llegaran las 
grandes obras! Y no sólo vaticinó el desarrollo de la novela realista en Rusia, sino que ofreció una definición de la misma y de sus características de gran modernidad y vigencia y que recuerda - como dijimos - las teorías más desarrolladas de su compatriota Bajtín. La novela es para Belinski un género especial, pues es la síntesis de todos los géneros de poesía, no sólo existentes, sino también de los que potencialmente puedan existir. Es un método único que permite combinar la creación de mundos de imágenes con elementos de reflexión del autor, vincular lo objetivo y lo subjetivo; reúne los elementos épico, dramático y lírico en un solo género, que es potencialmente flexible, ilimitado, que se presta al desarrollo extremo de cada uno de sus elementos y a la infinita variedad estilística. En ella se vincula la reproducción de toda una sociedad junto con la representación de destinos y caracteres individuales. Obsérvese, ya para acabar, el siguiente texto al respecto (Valles y Davidenko, 2000):

La novela y el relato corto se han puesto ahora en cabeza de todos los demás géneros poéticos. En ellos se han concentrado todas las bellas letras, así que cualquier obra distinta parece a su lado algo exclusivo y accidental. Las razones están en la propia esencia de la novela y el relato como géneros poéticos. En ellos la ficción confluye mejor, con más comodidad que en ningún otro género poético, con la realidad; la invención artística se mezcla con la copia simple, con tal que sea fiel, de la naturaleza (...). Es el género más amplio, más omnímodo de la poesía, en él el talento se siente infinitamente libre. En él se unen todos los demás géneros de la poesía: la lírica como expresión de los sentimientos del autor con motivo del acontecimiento que él describe, y la dramática como un modo que permite con más viveza y relieve hacer expresarse los caracteres. Las digresiones, las reflexiones, la didáctica, intolerables en otros géneros de la poesía, pueden tener en la novela y el relato su lugar legítimo. La novela y el relato dan una plena libertad al escritor en cuanto a la propiedad dominante de su talento, su carácter, gusto, tendencia, etc. Por eso hay tantos novelistas y autores de relatos en los últimos tiempos. Y por eso ahora los propios límites de la novela y el relato se han ensanchado.

\section{Referencias bibliográficas}

Bajtín, M. (1989). Teoría y estética de la novela. Madrid: Taurus.

Belinski, V. G. (1956). Selected Philosophical Works, Moscú: Foreign Languages Publishing House.

- (1976). Essais critiques. Moscú: Éditions du Progrès.

Bowman, H.E. (1954). Vissarion Belinski (1811-1848). A Study on the Origins of Social Criticism in Russia. Cambridge (Mass.): Harvard University Press. 
KulEshov, V. (1976). «Impétueux Vissarion». En BelinsKI (1976).

Lo Gatro, E. (ed.) (1925). Critici letterari russi. A cura. Foligno: Franco Campitelli.

- (1956). Storia della letteratura russa. Torino: Radio Italiana.

LotMAN, I. (1997). O russkoi literature. Petersburgo: Isskusstvo.

Nóvikova, O. (1997). Rusia y Occidente (Antología de textos). Madrid: Tecnos.

VALLES, J. (1996). «Primeras formulaciones». En Sociología de la literatura, A. Sánchez Trigueros (dir.), 24-35. Madrid: Síntesis.

- y DAVIDENKO, M. (2000). La crítica social-realista rusa del XIX (I). Textos de Belinski y Chernishevski. Almería: Universidad de Almería (en prensa).

VIllanUEVA, D. (1992). Teorías del realismo literario. Madrid: Espasa Calpe. WELLEK, R. (1972). Historia de la crítica moderna (1750-1950). Los años de transición. Madrid: Gredos, vol. 3.

Yovchuk, M. (1956). «A Great Russian Thinker». En Belinski (1956). 